\title{
CHARACTERISATION OF RECYCLED CONCRETE AGGREGATES WHEN USED IN ASPHALT CONCRETE. A TECHNICAL LITERATURE REVIEW
}

\author{
A.R. Pasandín ${ }^{a, *}$ and I. Pérez ${ }^{a}$ \\ ${ }^{a}$ Universidade da Coruña, E. T. S. I. Caminos, Canales y Puertos, Campus de Elviña s/n, 15071. A \\ Coruña, Spain \\ * Corresponding author. Tel.: +34-981167000. Fax: +34-981167170 \\ E-mail addresses: arodriguezpa@udc.es (A.R. Pasandín), iperez@udc.es (I.Pérez)
}

\begin{abstract}
Concrete is one of the most widely used construction and building materials. When a concrete structure reaches the end of its life, the demolition waste may be used to produce recycled concrete aggregates (RCA). RCA mainly differ from natural aggregates in the attached mortar that remains onto RCA surface. The differences between the properties of RCA and those of natural aggregates will condition the performance of the construction materials that contain RCA. Specifically, asphalt concrete (AC) that contains RCA has many technical disadvantages due to the porous nature of the attached mortar and thus, the high water and bitumen absorption and the low resistance to fragmentation of the RCA. However, some authors have experimented with the application of treatments to the RCA that allow its successful use in the manufacture of $\mathrm{AC}$, which contributes to sustainable development. This paper reviews the main properties of the RCA, particularly when used to produce AC.

Keywords: Recycled Concrete Aggregates; Porous attached mortar; Mechanical Properties; Physical Properties; Asphalt Concrete.
\end{abstract}




\section{Introduction}

The efforts to recycle and reuse materials contained in construction and demolition waste (CDW) are mainly driven by a need for sustainable development. Thus, the use of recycled concrete aggregates (RCA) from CDW has been growing in recent years, particularly as aggregates for concrete (Butler et al., 2011; Evangelista and de Brito, 2014; Koenders et al., 2014; Shi-Cong et al., 2014), unbound pavement layers (Chi Sun and Dixon, 2006; NCHRP, 2008; Robinson Jr. et al., 2004) and asphalt concrete (AC) (Cupo-Pagano et al., 1994; Shen and Du, 2004 and 2005; Paranavithana and Mohajerani, 2006; Pérez et al., 2007; Tam et al., 2007; Wong et al., 2007; Gul et al., 2008; Mukhopadhyay et al., 2010; Pérez et al., 2010; Mills-Beale and You, 2010; Rafi et al., 2011; Bushal et al., 2011; Lee et al., 2012; Pérez et al., 2012a and 2012b; Zhu et al., 2012; Arabani and Azarhoosh, 2012; Muniz de Farias et al., 2012; Pasandín and Pérez, 2013 and 2014).

Many researchers have stated that the poor quality (i.e., low density and porosity) of RCA is primarily due to the porous nature of the mortar cement attached onto the RCA surface (figure 1) (Cupo-Pagano et al., 1994; Paranavithana and Mohajerani, 2006; Pérez et al., 2007; Tam et al., 2007; Gul, 2008; Lee et al., 2012, Pérez et al., 2012b, Sánchez de Juan and Alaejos Gutiérrez, 2009). However, removing impurities, such as wood, glass, metal or gypsum, is also advisable in order to improve the final quality of RCA (Cupo-Pagano et al., 1994; Paranavithana and Mohajerani, 2006; Pérez et al., 2007; Pérez et al., 2012a and 2012b). Moreover, the small cracks produced by the crushing process (Tam et al., 2007) and the weak bond between the attached mortar and the original aggregate (Lee et al., 2012) are other factors to take into account.

Moreover, the quality of the RCA is highly variable, much like its composition, because it depends on the structure that was demolished to produce RCA as well as the manufacturing process. Therefore, the quality of RCA is heterogeneous (Paranavithana and Mohajerani, 2006; Gul, 2008).

Thus, RCA from CDW is a poorer-quality aggregate than natural aggregate (Lee et al., 2012; Sánchez de Juan and Alaejos Gutiérrez, 2009). Differences between the characteristics of natural aggregates and those of RCA will influence the performance of construction materials that contain RCA. The RCA content (between $0 \%$ and 100\%) is also expected to affect the material performance. However, RCA from CDW share a number of common features that coincide with most research. This paper presents an overview of the main properties of RCA for their use in construction and building materials, particularly AC. To compare the results obtained in the technical literature review, a typical Spanish RCA was used as 
a control RCA aggregate. The control RCA (figure 1) was obtained from demolition waste from residential buildings of different origins and qualities in Madrid (Spain) and was supplied by a CDW recycling plant.

\section{Particle size distribution. Changes in particle size distribution.}

The particle size distribution of RCA depends on the crushing process (Rueda Páramo, 2011). Fine and coarse fractions can be obtained (figure 2). The particle size distribution of the coarse fraction ( $\geq 4 \mathrm{~mm})$ is suitable for almost all RCA applications in the construction sector that require a granular material (CEDEX). The coarse fraction content ranges between $70 \%$ and $90 \%$ of the total weight of the original concrete (CEDEX) depending on the maximum size of the RCA and the composition of the original CDW (Rueda Páramo, 2011).

Notably, the particle size distribution of RCA was adequate for wet mix macadam in a study conducted in 74 recycling plants in Spain between 2009 and 2010 (GERD), although the percentage of filler generally was excessive and required correction at the plant.

Some studies (Paranavithana and Mohajerani, 2006; Gul, 2008) have determined the change in the particle size distribution of the AC due to mixing and compacting it with RCA. Furthermore, Arabani and Azarhoosh (2012) stated that the use of coarse fraction of RCA affects the mechanical properties of the $\mathrm{AC}$ because the mixing and compaction operations alter the size of the aggregate and separate the attached mortar cement. In addition, other relevant factors could affect the particle size distribution. Muniz Farias et al. (2012) highlighted the initial particle size of the AC, the compaction energy and the water content. Figure 3 shows the changes in the particle size distribution of an AC after the mixing and compacting operations. An AC 22 base B50/70 G was chosen according to the upper and lower limits given by the Spanish General Technical Specifications for Roads and Bridges, also known as PG-3 (Ministerio de Fomento, 2008). As shown in figure 3, the AC was manufactured using $30 \%$ of the control RCA. To compare the results, the AC was also manufactured using $0 \%$ of the control RCA. As expected, the particle size distribution changes of the AC that contains $30 \%$ of RCA are greater than those of the mixture that contains $0 \%$ of RCA (figure 3). In fact, the particle size distribution of the AC that contains $30 \%$ of RCA after the mixing and compacting operation is almost outside the zone specified by the PG-3 for an AC 22 base B50/70 G. The mixing and compaction operations lead to changes in the particle size distribution, but these changes are particularly noticeable when AC contains RCA mainly due to the weakness of the attached mortar. 


\section{Mechanical and physical properties}

\subsection{Resistance to the fragmentation}

An aggregate must be highly resistant to fragmentation in order to withstand traffic loads without cracking. The Los Angeles (LA) abrasion coefficient is a measure of the resistance to fragmentation of the aggregates: the smaller the LA of an aggregate, the greater its resistance to fragmentation. The LA of the RCA (table 1) varies over a wide range; it ranges between $25 \%$ and $45 \%$ depending on various parameters, such as the particle size, the quality of the original concrete and the LA of the original natural aggregate (Rueda Páramo, 2011). As shown in table 1, the LA of RCA is high (Shen and Du, 2004 and 2005; Pérez et al., 2007; Pérez et al., 2012a and 2012b). Thus, RCA is less resistant to fragmentation than natural aggregates, mainly because the attached mortar is easily fragmented during the LA test. The porous nature of the attached mortar, its lower resistance and the presence of cracks primarily result in the mortar being sprayed during the LA test (Rueda Páramo, 2011; Jiménez et al., 2011). Therefore, increasing mortar content also increases the LA (Sánchez de Juan and Alaejos Gutiérrez, 2009) because the loss of the self- weight of the original natural aggregate in this test should result in weight loss due to the disintegration of the attached mortar. Thus, the RCA fine fraction, whose mortar content is high (Sánchez de Juan and Alaejos Gutiérrez, 2009), is less resistant to fragmentation than the coarse fraction.

\subsection{Density and water absorption}

Table 1 also shows the bulk specific density $\left(\rho_{\mathrm{a}}\right)$ and the water absorption $\left(\mathrm{WA}_{24}\right)$ of the RCA and the natural aggregates. This table indicates that the RCA are less dense than the natural aggregates (CupoPagano et al., 1994; Shen and Du, 2004 and 2005; Paranavithana and Mohajerani, 2006; Pérez et al., 2007; Wong et al., 2007; Pérez et al., 2010; Rafi et al., 2011; Pérez et al., 2012a and 2012b). In general, the density values of RCA are between 5\% and 10\% lower than those of natural aggregates (CEDEX). Therefore, AC that contains RCA is also less dense than conventional mixtures.

The content of attached mortar has been shown to negatively correlate with the density (Sánchez de Juan and Alaejos Gutiérrez, 2009). Therefore, the differences between the densities of RCA and natural aggregates are more pronounced in the fine fraction because its mortar content is higher (CEDEX). As illustrated in table 1, one of the most important differences between the RCA and the natural aggregates is the water absorption (CEDEX). This property is also directly related to the mortar content; the mortar content positively correlates with water absorption (Sánchez de Juan and Alaejos Gutiérrez, 
2009). Because the mortar content of the fine fraction is higher than that of the coarse fraction (Sánchez de Juan and Alaejos Gutiérrez, 2009), it also absorbs more water than the coarse fraction.

Therefore, RCA absorbs more water than natural aggregates (Shen and Du, 2004 and 2005; Paranavithana and Mohajerani, 2006; Pérez et al., 2007; Gul, 2008; Pérez et al., 2010; Rafi et al., 2011; Pérez et al., 2012a and 2012b). The water absorption values range between $4 \%$ and $9 \%$ or even higher values, i.e., between $5 \%$ and $15 \%$ for recycled sand (CEDEX).

Attached mortar is a porous material (Paranavithana and Mohajerani, 2006; Pérez et al., 2007; Pérez et al., 2010; Pérez et al., 2012a and 2012b; Sánchez de Juan and Alaejos Gutiérrez, 2009). Thus, RCA is not only less dense and absorbs more water, but it is also more porous (Paranavithana and Mohajerani, 2006) and permeable (Gul, 2008).

\section{Geometrical properties}

\subsection{Shape}

Flat particles are more likely to break when subjected to the stresses caused by traffic loads; thus, their content should be limited. The equipment used to crush both RCA and natural aggregates influences the shape of the aggregates. Impact crushers tend to form cubic-angular shaped particles (GERD, 2010). Furthermore, concrete tends to break into small blocks, which generates small amounts of flat particles (GERD, 2010). RCA generally contains a lower proportion of flat particle than natural aggregates (CEDEX), ranging between 5\% and 9\% (GERD, 2010). In addition to the reasons stated above, the lower flat particle content could also be due to the attached mortar, which increases the thickness of the flat particles (Rueda Páramo, 2011). This hypothesis is consistent with the limited research conducted to date, which concluded that RCA meets the specifications for the flakiness index for manufacturing AC (Pérez et al., 2007, Pérez et al., 2010; Mills-Beale and You, 2010; Pérez et al., 2012a and 2012b). The flakiness index (IL) of the control RCA is 8\%, which complies with PG-3 (Ministerio de Fomento, 2008) in the highest heavy traffic category, T00 (Traffic category T00 refers to Annual Average Daily Heavy Traffic $\geq 4,000)$.

\subsection{Per cent fractured face of coarse aggregate}

A high percentage of fractured faces is desirable for the aggregates because fractured faces improve the strength of the pavement layers due to the internal friction and the strong interlock between aggregates. Previous studies have indicated that RCA are generally angular due to the crushing process to which they are subjected during their manufacturing process (Adams, 2012); thus, they also contain a high 
percentage of fracture faces. The limited research conducted to date on this property concluded that RCA meets the specifications on fracture faces to manufacture AC (Pérez et al., 2007; Pérez et al., 2010; MillsBeale and You, 2010; Bushal et al., 2011; Pérez et al., 2012a and 2012b). The control RCA contains $85.48 \%$ fractured faces, which complies with the Spanish specification PG-3 (Ministerio de Fomento, 2008) for the heavy traffic category T3 (Traffic category T00 refers to Annual Average Daily Heavy Traffic ranging 50 to 200). The state of the art results imply a higher percentage of crushed particles. However, such high percentages were not observed. This result highlights the weakness of the mortar attached on the RCA surface, which does not lead to sharp edges, but rounded ones, after the crushing process. Furthermore, RCA could present contain rounded natural aggregates because their inclusion is advisable for the workability of concrete, which could also partly explain these results.

\subsection{Surface texture}

The roughness and irregularities of the surface aggregates are included under the term texture (NCHRP, 2008). The RCA are rougher than the natural aggregates (Shen and Du, 2004 and 2005) due to the presence of attached mortar. As a result, the internal friction of RCA is greater than that of natural aggregates, but coating RCA with binder during the AC manufacturing process is also more difficult.

\subsection{Clay or plastic fines and dust}

A very low sand equivalent (SE) value is well known to indicate that the aggregate contains an excess of dust or plastic fine particles. These aggregates should not be used for pavement layers because they could affect their strength and durability. The fine clay can compromise the adhesion of the aggregate with the binder and even expand. Furthermore, the presence of water can lead to internal friction losses.

During the RCA manufacturing process, the fine fraction consists exclusively of concrete in order to ensure high values of the sand equivalent (GERD, 2010). Limited investigations of this property indicate that RCA meet the specifications for the sand equivalent for manufacturing AC (Pérez et al., 2007; Pérez et al., 2010; Pérez et al., 2012a and 2012b). The sand equivalent value of the control RCA was 67\%, which complies with the Spanish specifications (Ministerio de Fomento, 2008) for the manufacture of AC.

\subsection{RCA composition}

Jiménez et al. (2011) studied three types of RCA. They concluded that these RCA were very pure because over $96 \%$ of the particles were concrete (between $71 \%$ and $76 \%$ were aggregates with attached mortar and between $20 \%$ and $25 \%$ were aggregates without attached mortar). The remaining components are 
considered to be impurities. Thus, this material contained between $1.6 \%$ and $3.5 \%$ ceramics, between $0 \%$ and $0.3 \%$ asphalt, between $0 \%$ and $0.1 \%$ gypsum and no significant amounts of wood, glass, plastic, metal, natural soil and light particles. All of these values are represented in figure 4. The control RCA contained $89.3 \%$ petrous materials, i.e., its impurity content was higher.

Conversely, the content of attached mortar, which as discussed above primarily results the lower quality of RCA compared to natural aggregates, is highly variable, ranging between $25 \%$ and $70 \%$ by mass based on the fraction of aggregate considered (Sánchez de Juan and Alaejos Gutiérrez, 2009). In this sense, the attached mortar contents of the finer fractions are higher than those of the coarser fractions (Sánchez de Juan and Alaejos Gutiérrez, 2009). The mortar content also depends on the type of original natural aggregate, the dosage of the original concrete and the crushing process (MDOT, 2011).

\section{Other properties}

\subsection{Self-cementing properties}

The resistance has been shown to increase over time when using RCA as a granular material due to the RCA self-cementing properties (Chi Sun and Dixon, 2006; Arm, 2001). The presence of non-hydrated cement in the attached mortar is largely responsible for this phenomenon (Chi Sun and Dixon, 2006; FHWA, 2004). This property has not been studied for the use of RCA in manufacturing AC due to the nature of this type of material.

\subsection{RCA affected by alkali-silica reactions}

The alkali-silica reaction (ASR) is a deleterious chemical reaction (Xiao Gao et al., 2013): in the presence of water, the alkaline solution of the pores of the concrete reacts with silicate minerals that are part of the composition of some aggregates. The resulting products are expansive and may lead to crack formation (Saccani and Bignozzi, 2010).

A consensus on the use of RCA affected by ASR in AC is lacking. Thus, some studies indicate that this type of reaction is not deleterious if the RCA is to be used for manufacturing AC (MDOT, 2011). In contrast, other studies (Mills-Beale and You, 2010) have questioned its viability. Studies have indicated that RCA affected by ARS can be used in AC, but with certain precautions. For example, the use of the fine fraction or mineral powder and activating agents of the adhesiveness (anti- stripping) should be avoided because the latter can enhance the adverse effects of this type of aggregate (Mukhopadhyay, 2010). Furthermore, the locations where AC that contains RCA affected by ASR will be used should be carefully selected. In particular, these aggregates are not suitable for airport runways, which experience 
severe shocks as a result of landing aircraft, because RCA affected by ASR reactions often experience microcracks and thus are more likely to mechanically degrade (Mukhopadhyay, 2010).

\subsection{Bitumen content and bitumen absorption}

As shown in table 2, the AC that involves RCA contains more optimum binder (Bo) than conventional mixtures (Shen and Du, 2004 and 2005; Pérez et al., 2007; Wong et al., 2007; Pérez et al., 2010; Rafi et al., 2011; Bushal et al., 2011; Muniz de Farias et al., 2012) due to the high porosity of the attached mortar (Wong et al., 2007; Muniz de Farias et al., 2012). This difference is more apparent when RCA substitution is performed in the fine fraction (Rafi et al., 2011), which, as stated above, contains more mortar (Sánchez de Juan and Alaejos Gutiérrez, 2009) and a higher specific surface area (Rafi et al., 2011). Furthermore, Bushal et al. (2011) indicated that the optimum binder content increases linearly with the percentage of substitution of RCA in the mixture.

Table 2 shows the strong differences between the optimum binder content obtained for the same RCA percentage by different authors. These differences between researchers might be due to several reasons: the impurity content of the RCA used to make the AC because some impurities, such as gypsum, may increase the demand for binder; the fractions used in the RCA because the fine fraction demands more binder (as mentioned above); and the rules and specifications of the different countries. This latter consideration may be decisive in determining the optimum binder content. For example, the Florida Department of Transportation (FDOT) requires a minimum of 5\% effective binder content (Pbe) (Jajliardo, 2003), i.e., a minimum of $5 \%$ of binder that has not been absorbed by the aggregate. In contrast, this minimum is not enforced in Spain. Instead, the minimum binder content in the mixture is 3.5\% (Ministerio de Fomento, 2008). Therefore, the required bitumen will be higher in this example if the mixture is dosed following FDOT specifications rather than Spanish specifications.

The voids filled with asphalt (VFA) content is related to the durability of the mixture. A lower VFA can lead to a lower durability of AC materials (Murphy and Bentsen, 2001), especially if this lower VFA is due to a low effective binder content. Some studies (Paranavithana and Mohajerani, 2006; Mills-Beale and You, 2010) have indicated that the effective binder content of AC that contains RCA is lower than that of conventional mixtures because the high bitumen absorption $(\mathrm{Pba})$ of the RCA causes less binder to coat the aggregate (Paranavithana and Mohajerani, 2006). Again, the primary responsibility of this feature is the absorbent nature of the mortar attached on the RCA surface. Moreover, bitumen absorption is a function of the binder content. Therefore, as shown in figure 5, the RCA content positively correlates with 
the bitumen absorption (Bushal et al., 2011). When the fine fraction is replaced with RCA, the bitumen absorption increases. For economic reasons, Bushal et al. (2011) propose that this substitution be made in the coarse fraction to prevent greater optimum binder contents.

\section{Treatments applied to the RCA in order to improve their properties}

Only few studies have examined treatments that help to improve the properties of RCA. Wong et al. (2007) subjected the RCA to a calcination process. In this process, lime was obtained from the calcite present in the RCA. Therefore, the mineral powder obtained from the RCA contained a certain amount of lime, which is commonly used to improve the properties of the AC. Furthermore, Wong et al. (2007) found that the calcination process reduced the grain size of the RCA. The results of this treatment were satisfactory.

Other researchers (Mills-Beale and You, 2010) highlighted the absorbent behaviour of RCA under dynamic loads, which indicated that the use of sealants minimise binder absorption by the porous RCA.

Lee et al. (2012) coated RCA with a cement paste to reinforce RCA weakened by small cracks that appear during the crushing process. At an optimum cement thickness, Los Angeles coefficient of the coated RCA was lower and its resistance was higher than that of the uncoated material.

Zhu et al. (2012) used RCA from the demolition of buildings affected by the earthquake in Wenchuan (China) to produce AC. Because the RCA contained $28.46 \%$ ceramics and bricks, a highly absorptive and poorly resistant RCA was expected. Therefore, they coated the RCA with a patented liquid silicone resin. The analysis of the physical properties of aggregates by Zhu et al. (2012) indicated that this treatment improves both the absorption of RCA as its resistance to fragmentation. Thus, the treatment improved the adhesiveness of the brick and the ceramic present in the RCA.

Pasandín and Perez (2013 and 2014) tested two treatments: coating the RCA with a bituminous emulsion prior to the manufacture of $\mathrm{AC}$ or curing loose mixture in the oven for 4 hours at the mixing temperature prior to compaction. Both treatments significantly improved the water resistance of the AC.

\section{Conclusions}

RCA differs from natural aggregates primarily because it contains attached mortar (Sánchez de Juan and Alaejos Gutiérrez, 2009). Researchers have primarily attributed the reduced quality of RCA compared to natural aggregates to the presence of mortar and various impurities, as well as to the weak contact between the natural aggregate and cement mortar and the appearance of small cracks as a result of the crushing process (Cupo-Pagano et al., 1994; Paranavithana and Mohajerani, 2006; Pérez et al., 2007; Tam 
et al., 2007; Gul, 2008, Pérez et al., 2010; Lee et al., 2012; Pérez et al., 2012a and 2012b; Sánchez de Juan and Alaejos Gutiérrez, 2009). Thus, RCA will absorb more water and be less dense than natural aggregates (Cupo-Pagano et al., 1994; Shen and Du, 2004 and 2005; Paranavithana and Mohajerani, 2006; Pérez et al., 2007; Wong et al., 2007; Pérez et al., 2010; Rafi et al., 2011; Pérez et al., 2012a and 2012b; CEDEX). RCA also differs from natural aggregates in other properties; it is less resistant to fragmentation (Shen and Du, 2004 and 2005; Pérez et al., 2007; Pérez et al., 2010; Rafi et al., 2011; Pérez et al., 2012a and 2012b), and its particle size distribution changes somewhat after the mixing and compaction processes (Paranavithana and Mohajerani, 2006; Gul, 2008; Arabani and Azarhoosh, 2012; Muniz de Farias et al., 2012). The difference between the properties of RCA and natural aggregates conditions the behaviour of AC that contains partial replacements of RCA. However, the use of treatments (Lee et al., 2012; Zhu et al., 2012; Pasandín and Pérez, 2013 and 2014), such as coating the RCA with various products, letting the mixture cure in an oven or the calcination of RCA, have been proven to be highly effective in solving all of these problems.

\section{Acknowledgements}

The authors wish to acknowledge the Spanish Ministry of Education and Science for sponsoring this research through Project BIA2010-17751.

The authors would also like to thank Nynas bitumen for supplying the binder required for this study, TecRec for supplying the recycled aggregates, Probigasa for supplying the natural aggregates and Cosmos for supplying the Portland cement.

\section{References}

Adams, M.P. Alkali-Silica Reaction in Concrete Containing Recycled Concrete Aggregates, An Abstract of the thesis, Oregon State University, 2012.

Arabani, M.; Azarhoosh, A.R. The effect of recycled concrete aggregate and steel slag on the dynamic properties of asphalt mixtures, Constr Build Mater 35 (2012) 1-7.

Arm, M. Self-cementing properties of crushed demolished concrete in unbound layers: results from triaxial tests and field tests, Waste Manage 21 (2001) 235-239.

Bushal, Sushanta; Li, Xiaojun; Wen, Haifang. Evaluation of Effects of Recycled Concrete Aggregate on Volumetrics of Hot-Mix Asphalt, Transport Res Rec 2205:3 (2011) 36-39.

Butler, L.; West, J.S.; Tighe, S.L. The effect of recycled concrete aggregate properties on the bond strength between RCA concrete and steel reinforcement, Cement Concrete Res 41 (2011) 1037-1049. CEDEX, Catálogo de residuos [online], Ministerio de Fomento y Ministerio de Medio Ambiente y Medio Rural y Marino. http://www.cedexmateriales.vsf.es/view/default.aspx.

Chi Sun, Poon; Dixon, Chan. Feasible use of recycled concrete aggregates and crushed clay brick as unbound road sub-base, Constr Build Mater 20 (2006) 578 - 585.

Cupo-Pagano, M.; D’Andrea, A.; Giavarini, C.; Marro, C. Use of building demolition waste for asphalt mixes: first result, Energy, environment and technological innovation, Proceedings of III International Congress, 1994, pp. 203 - 208.

Evangelista, L.; de Brito, J. Concrete with fine recycled aggregates: a review, European Journal of Environmental and Civil Engineering (2014) 129-172.

FHWA, Transportation Applications of Recycled Concrete Aggregate, 2004. 
GERD, Control de los Residuos de Construcción y Demolición, RCD, en los Ayuntamientos, Spain, 2010.

GERD, Guía Española de áridos reciclados procedentes de RCD [online]. www.caminospaisvasco.com.

Gul, Waqar Ahmed. Effect of Recycled cement concrete content on rutting behaviour of asphalt concrete, Doctoral Thesis, Middle East Technical University, Ankara, 2008.

Jajliardo, A.P. Development of Specification Criteria to Mitigate Top-down Cracking, Master's Thesis, Universtity of Florida, 2003.

Jiménez, J.R..; Agrela, F.; Ayuso, J.; López, M. Estudio comparativo de los áridos reciclados de hormigón y mixtos como material para sub-bases de carreteras, Mater Construcc 61:302 (2011) 289-302. Koenders, Eduardus A.B.; Pepe, Marco; Martinelli, Enzo. Compressive strength and hydratation processes of concrete with recycled aggregates, Cement Concrete Res 56 (2014) 203-212.

Lee, Cheng-Hsiao; Du, Jia-chong; Shen, Der-Hsien. Evaluation of pre-coated recycled concrete aggregate for hot mix asphalt, Constr Build Mater 28 (2012) 66-71.

MDOT, Using Recycled Concrete in MDOT's Transportation Infraestructure-Manual of Practice, Final Report, 2011.

Mills-Beale, Jualian; You, Zhanping. The mechanical properties of asphalt mixtures with recycled concrete aggregates, Constr Build Mater 24 (2010) 340-345.

MINISTERIO DE FOMENTO. O.C. 24/08 sobre el Pliego de Prescripciones Técnicas Generales para obras de carreteras y puentes (PG-3). Artículo: 542-Mezclas bituminosas en caliente tipo hormigón bituminoso; 2008.

Mukhopadhyay, Anol K.; Geiger, Brian J.; Button, Joe. Use of Alkali-Silica Reaction-Affected Recycled Concrete Aggregate in Hot-Mix Asphalt, Transport Res Rec 2179 (2010) 1-9.

Muniz de Farias, M.; Quiñones Sinisterra, F.; Gómez Jiménez, A.M.; Ribeiro e Souza, M.V.; Farias Falcão, P.R. Influence of Asphalt Rubber on the Crushing of Recycled Aggregates Used in Dense HMA, Proceedings of Asphalt Rubber, 2012

Murphy, T.; Bentsen, R.A. Marshall mix design: Getting the most of your Marshall mixes, Humboldt product manual, 2001.

NCHRP, Report 598. Performance-Related Test of Recycle Aggregates for Use in Unbound Pavement Layers, Transportation Research Board, 2008.

NCHRP. Report 598. Performance-Related Test of Recycle Aggregates for Use in Unbound Pavement Layers, Transportation Research Board, 2008.

Paranavithana, Sumeda; Mohajerani, Abbas. Effects of recycled concrete aggregates on properties of asphalt concrete, Resour Conserv Recy 48 (2006) 1-12.

Pasandín, A.R.; Pérez, I. Ageing time influence on properties of hot-mix asphalt made with recycled concrete aggregates, Constr Build Mater 52 (2014) 284-293.

Pasandín, A.R.; Pérez, I. Laboratory evaluation of hot-mix asphalt containing construction and demolition waste, Constr Build Mater 43 (2013) 497-505.

Pérez, I.; Gallego, J.; Toledano, M.; Taibo, J. Asphalt mixtures with construction and demolition debris, Proceedings of the Institution of Civil Engineers. Transport 163 (2010) 165-174.

Pérez, I.; Pasandín, A.R.; Gallego, J. Stripping in hot mix asphalt produced by aggregates from construction and demolition waste, Waste Manage Res 30:1 (2012a) 3-11.

Pérez, I.; Pasandín, A.R.; Medina, L. Hot mix asphalt using C\&D waste as coarse aggregates, Mater Design 36 (2012b) 840-846.

Pérez, I.; Toledano, M.; Gallego, J.; Taibo, J. Mechanical properties of hot mix asphalt made with recycled aggregates from reclaimed construction and demolition debris, Mater Construcc 57:285 (2007) $17-29$.

Rafi, Muhammad Masood; Qadir, Adnan; Siddiqui, Salman Hameed. Experimental testing of hot mix asphalt mixture made of recycled aggregates, Waste Manag Res 29:12 (2011) 1316-1326.

Robinson Jr., Gilpin R.; Menzie, W. David; Hyun, Helen. Recycling of construction debris as aggregate in the Mid-Atlantic Region, USA, Resour, Conserv Recy 42 (2004) 275-294.

Rueda Páramo, A. Tipología de áridos reciclados en Cataluña y su aplicabilidad, Master Thesis, Universitat Politècnica de Catalunya, Spain, 2011.

Saccani, A.; Bignozzi, M.C. ASR expansion behavior of recycled glass fine aggregates in concrete, Cement Concrete Res 40 (2010) 531-536.

Sánchez de Juan, M.; Alaejos Gutiérrez, P. Study on the influence of attached mortar content on the properties of recycled concrete aggregate, Constr Build Mater 23 (2009) 872-877.

Shen, Der-Hsien; Du, Jia-chong. Application of Gray Rational Analysis to Evaluate HMA with Reclaimed Building Materials, J Mater Civil Eng 17 (2005) 400-406.

Shen, Der-Hsien; Du, Jia-chong. Evaluation of building materials recycling on HMA permanent deformation, Constr Build Mater 18 (2004) 391-397. 
Shi-Cong, Kou; Bao-jian, Zhan; Chi-Sun, Poon. Use of a $\mathrm{CO}_{2}$ curing step to improve the properties of concrete prepared with recycled aggregates, Cement Concrete Comp 45 (2014) 22-28.

Tam, Vivian W.Y. ; Tam, C.M.; Le, K.N. Removal of cement mortar remains from recycled concrete aggregate using pre-soaking approaches, Resour Conserv Recy 50 (2007) 82-101.

Wong, Yiik Diew; Delai Sun, Darren; Lai, Dickson .Value-added utilisation of recycled concrete in hotmix asphalt, Waste Manage 27 (2007) 294-301.

Xiao Gao, X.; Multon, S.; Cyr, M.; Sellier, A. Alkali-silica reaction (ASR) espansion: Pessimum effect versus scale effect, Cement Concrete Res 44 (2013) 25-33.

Zhu, J.; Wu, S.; Zhong, J.; Wang, D. Investigation of asphalt mixture containing demolition waste obtained from earthquake-damaged buildings, Constr Build Mater 29 (2012) 466-475. 
Figure 1

Detail of the attached mortar on the RCA surface

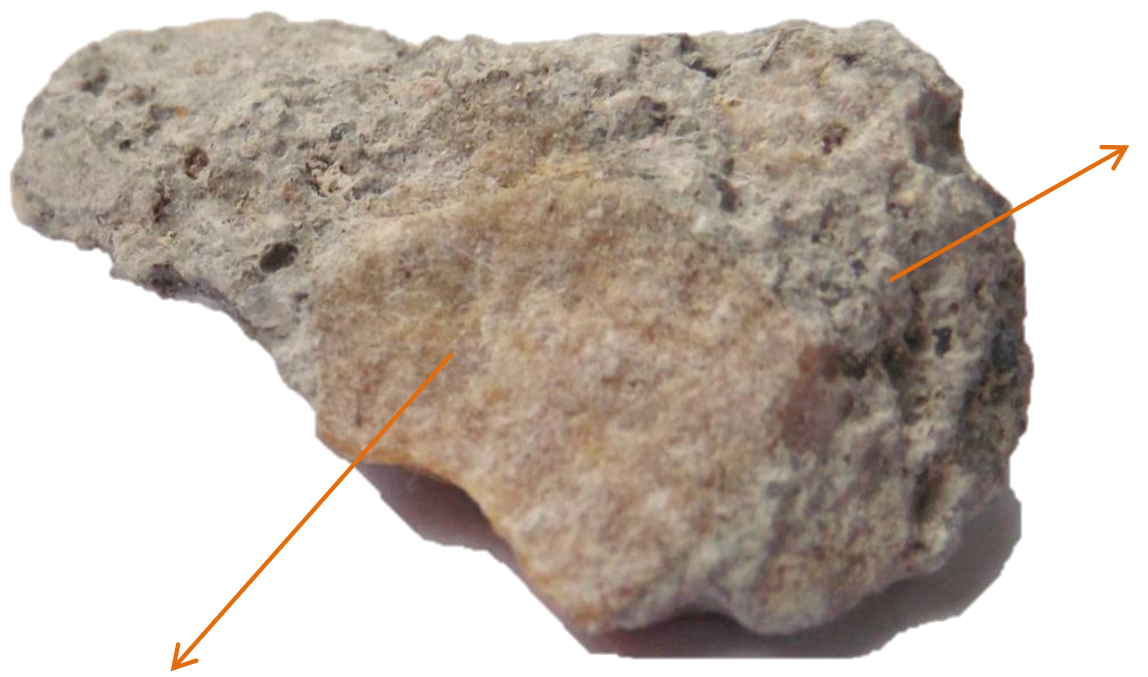

Porous attached mortar

Original aggregate

Figure 2

Particle size distribution of control RCA

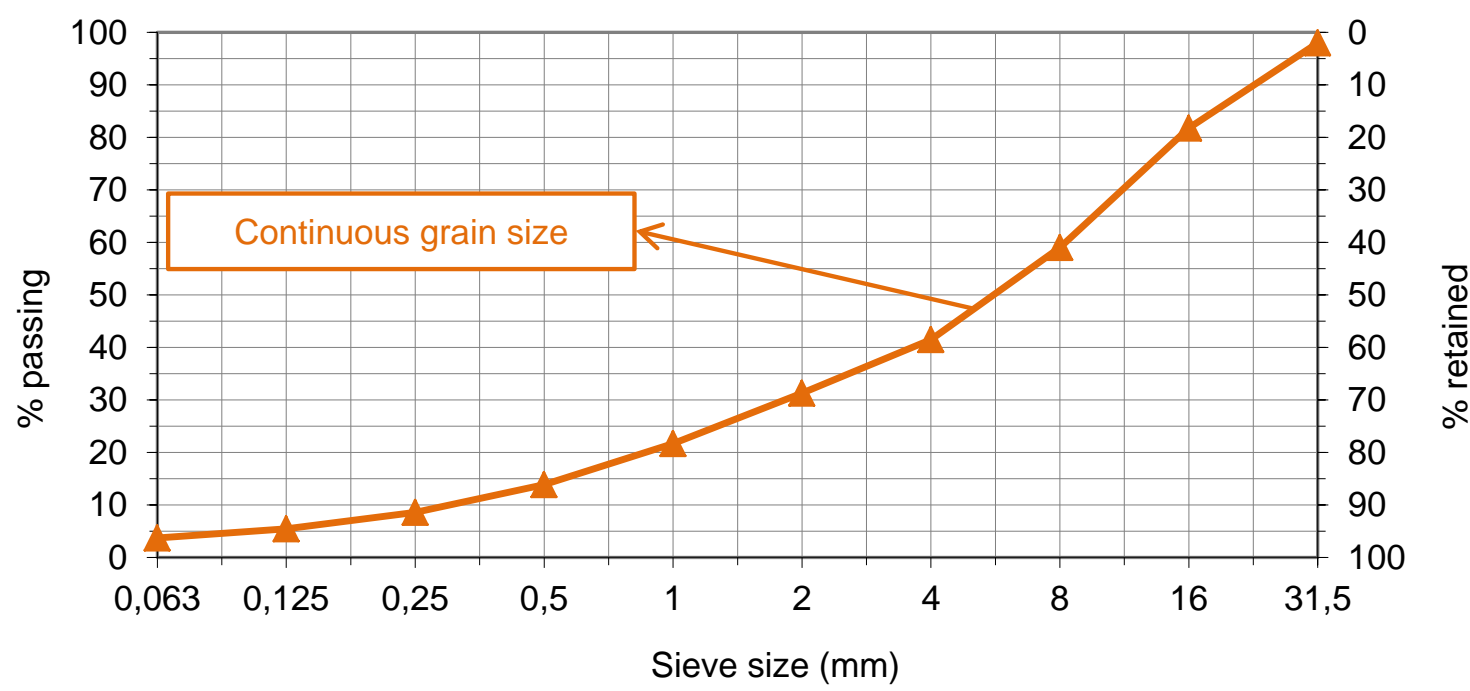


Figure 3

Changes in particles size distribution of an AC 22 base B50/70 G made with $0 \%$ and $30 \%$ of the control RCA

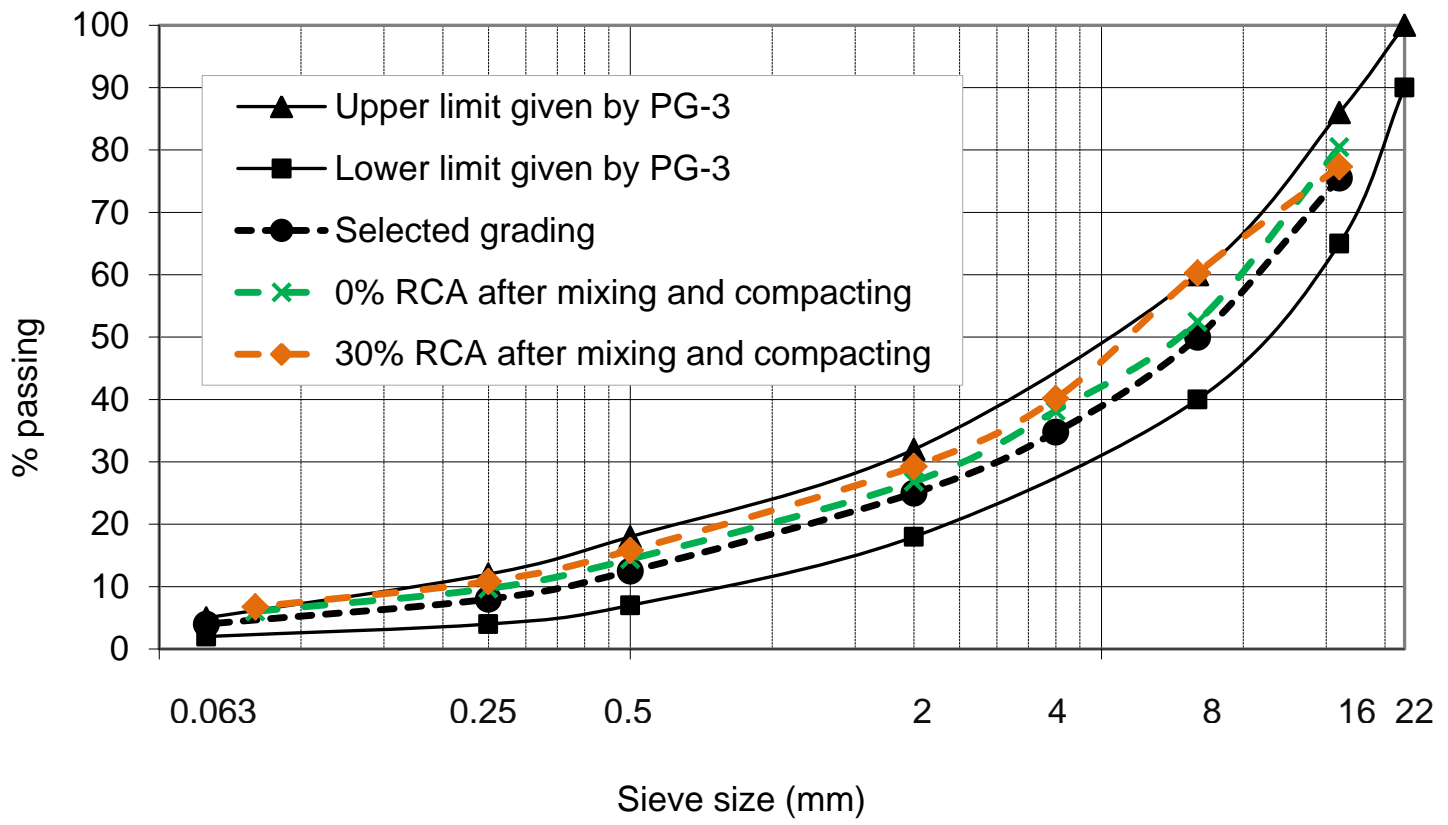

Figure 4

RCA composition according to Jiménez et al. [34].

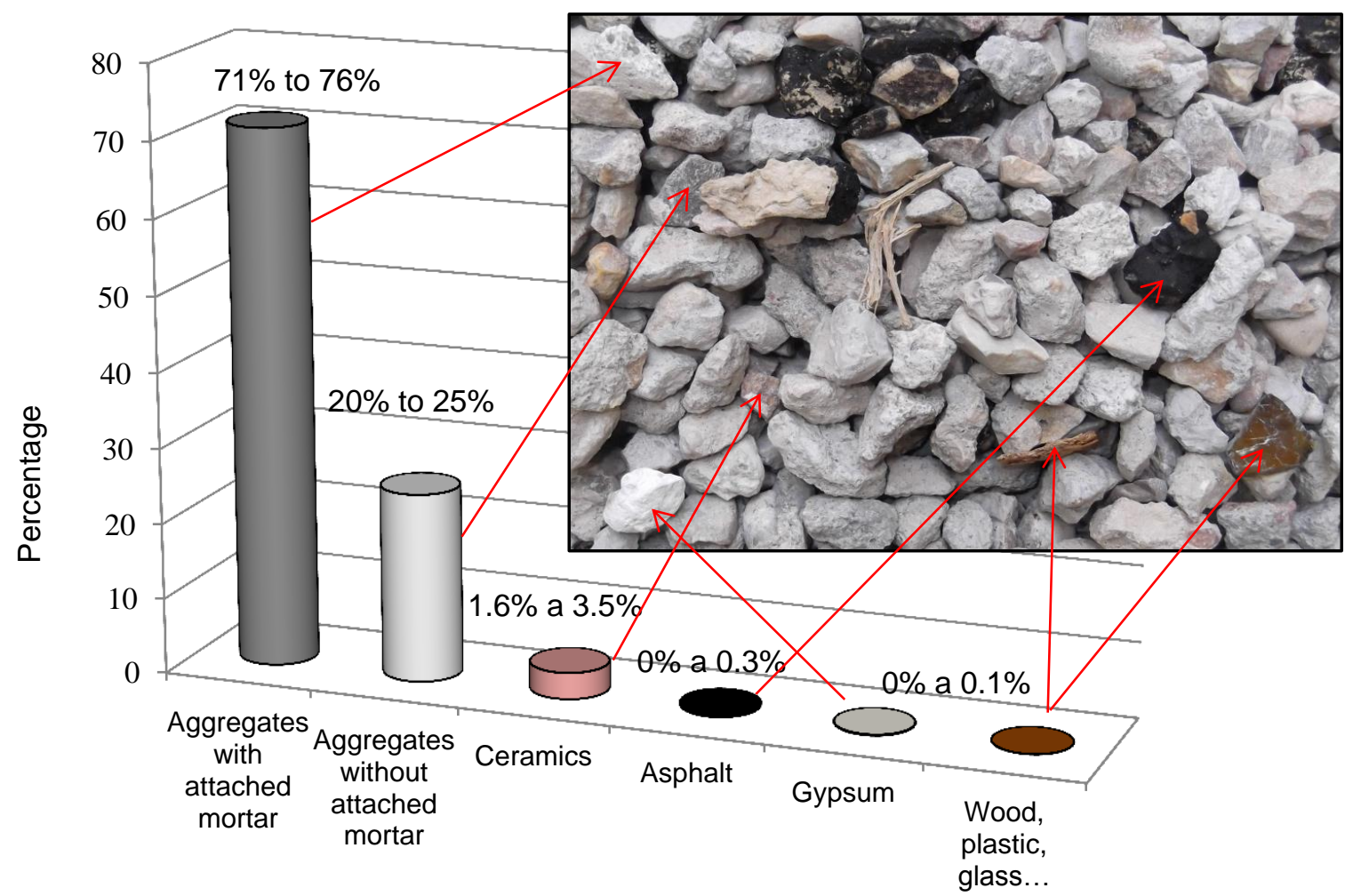


Figure 5

Bitumen absorption ( $\mathrm{Pba}$ ) versus RCA percentage according to Bushal et al. [20]

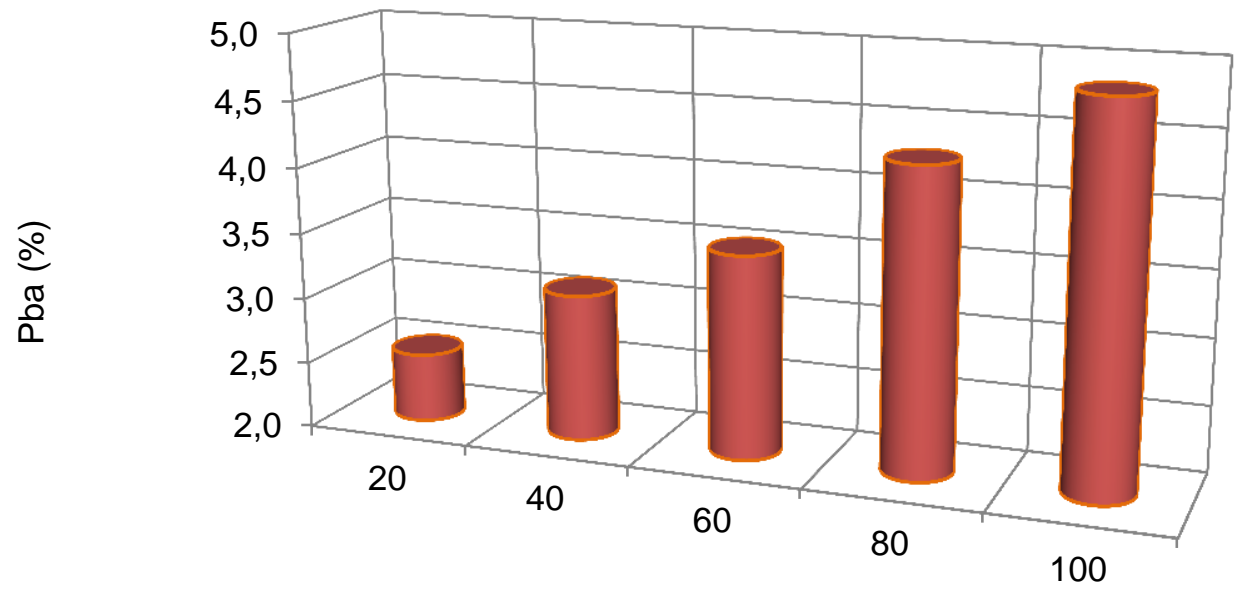

$\operatorname{RCA}(\%)$ 